\title{
LA PALABRA DE DIOS EN LA VIDA Y EL MINISTERIO DEL PASTOR
}

JORGE BLUNDA GRUBERT ${ }^{1}$

DOI: https://doi.org/10.52039/seminarios.v57i199-200.356

INTRODUCCIÓN

Nos disponemos a abordar el aspecto específicamente pastoral de este proceso eclesial que tuvo lugar con ocasión de la XII asamblea general del Sínodo de los Obispos del año 2008 y que dio como fruto más tangible la exhortación apostólica Verbum Domini del papa Benedicto XVI.

En realidad, la institución del Sínodo ya es, en sí misma, de carácter eminentemente pastoral, y la convocatoria de esta asamblea en cuestión así lo ponía en evidencia, al establecer como tema de las reflexiones y las discusiones «la Palabra de Dios en la vida y en la misión de la Iglesia». En consecuencia, todo el documento pontificio presenta esta orientación pastoral, incluidas las amplias consideraciones teóricas recogidas en el capítulo III de la primera parte: «La hermenéutica de la sagrada Escritura en la Iglesia» ${ }^{2}$. Éstas se fundan en la convicción de que «el modo de interpretar los textos bíblicos para los hombres y las mujeres de nuestro tiempo tiene consecuencias directas para su relación personal y comunitaria con Dios y también está ligado estrechamente a la misión de la Iglesia» ${ }^{3}$.

Pero el encuadre pastoral de estas páginas tiene que ver, además, con la atención que queremos prestar a todo lo que este acontecimiento sinodal tiene que decir a los pastores, especialmente a los presbíteros. De ellos, en gran medida, depende que estas orientaciones pastorales lleguen a ponerse en práctica. Para asumirlas de verdad, necesitarán revisar y renovar en no pocos aspectos su propia vida ${ }^{4}$.

1. Sacerdote de la diócesis de Tucumán (Argentina). Doctor en Sagrada Escritura por el Pontificio Instituto Bíblico (Roma).

2. El papa lo explica cuando dice que «la eficacia pastoral de la acción de la Iglesia y de la vida espiritual de los fieles depende en gran parte de la fecunda relación entre exegesis y teología» (VD 31) y también: "La auténtica hermenéutica de la fe comporta ciertas consecuencias importantes en la actividad pastoral de la Iglesia» (VD 45).

3. JuAn Pablo II, Discurso ante la Pont. Com. Bíblica (23 de abril de 1993).

4. Por lo mismo, parece indispensable revisar también los contenidos, los medios, la pedagogía y las estructuras de la formación inicial, cf. J. BLUNDA, «La Palabra de Dios en la formación sacerdotal en orden al ministerio», Boletín OSAR 28 (2009), 4-77. 


\section{El CONTEXTO: UNA IGLESIA «EN ESTADO DE MISIÓN»}

Después de haber insistido tanto en la centralidad de la Eucaristía, «fuente y culmen de toda la vida eclesial $»^{5}$, ¿a qué viene ahora este renovado interés por la Palabra de Dios que se verifica en los diversos ámbitos geográficos y en todos los niveles jerárquicos de la Iglesia? Creo que se explica por una toma de conciencia del nuevo contexto en el que nos encontramos como Iglesia.

En un «régimen de cristiandad», en una sociedad que ha incorporado los valores y símbolos cristianos en su propia cultura y ha encontrado incluso el modo de expresarlos en sus formas propias y originales, la Iglesia podría dedicarse a mantener y alimentar la fe ya recibida, y a celebrarla gozosamente en los sacramentos y sacramentales. Pero hemos de reconocer que «ha pasado ya, incluso en los Países de antigua evangelización, la situación de una 'sociedad cristiana', la cual, aún con las múltiples debilidades humanas, se basaba explícitamente en los valores evangélicos» ${ }^{6}$.

En sociedades como las nuestras, la pastoral no se puede contentar con mantener y celebrar. Ha de afrontar con realismo, creatividad y esperanza el desafío de una «nueva evangelización ${ }^{7}$, reavivar el ardor de los orígenes apostólicos e impulsar «un nuevo tiempo misionero para todo el Pueblo de Dios». Sin descuidar la pastoral ordinaria, tendremos que salir a buscar a quienes no creen ni se sienten incluidos en la iglesia, y «anunciar persuasivamente la Palabra de Dios de manera que puedan experimentar concretamente la fuerza del Evangelio». Todo esto, pensando también en los «bautizados no suficientemente evangelizados», que viven «bajo la influencia de una cultura secularizada» (VD 96; cf. n. 122).

Así se entiende la recuperación creciente del valor de la Palabra de Dios en la vida y la misión de la Iglesia. En este «estado de misión», la prioridad la tiene el anuncio de la Palabra de Dios. No se puede evangelizar sin el Evangelio. Se trata de «evangelizar la cultura y las culturas de la humanidad», es decir, de «alcanzar y transformar con la fuerza del Evangelio los criterios de juicio, los valores determinantes, los puntos de interés, las líneas de pensamiento, las fuentes inspiradoras y los modelos de vida de la humanidad.... ${ }^{8}$.

Es verdad que los cristianos podemos contribuir de muchas maneras al bien de nuestra sociedad. Pero la comunicación de la Buena Noticia es la primera

5. Sacrosanctum Concilium, 10. Pensamos no sólo en el Sínodo anterior, sino también en las numerosas intervenciones doctrinales y disciplinarias sobre la Eucaristía del papa y de los diversos dicasterios romanos, realizadas durante estos últimos treinta años.

6. Juan Pablo II, Novo Millennio Ineunte, 40.

7. Juan Pablo II utilizaba por primera vez esta expresión en un llamamiento dirigido explícitamente a la Iglesia en América Latina en 1983 (Discurso en la XIX Asamblea Ordinaria del CELAM, Puerto Príncipe, Haití, 9-3-1983) al iniciar la novena de años previa a la conmemoración del quinto centenario de la evangelización de América. Ampliaba esta invitación a la Iglesia universal en 1990 que su encíclica Redemptoris Missio, 33.

8. Evangelii Nuntiandi, 19. 
deuda que la Iglesia tiene con el mundo y en ella se juega su identidad y su misión. «No hay prioridad más grande que ésta: abrir de nuevo al hombre de hoy el acceso a Dios, al Dios que habla y nos comunica su amor para que tengamos vida abundante» (VD 1).

\subsection{Una Iglesia al servicio del encuentro de los hombres con Cristo}

La evangelización no consiste, sin embargo, en la transmisión de unas luminosas ideas, ni en la difusión de un determinado modo de vida, sino en la comunicación de la propia experiencia de fe y de encuentro con el Señor, que nos ha cambiado la vida. Pues, según la feliz expresión del papa Benedicto XVI, «no se comienza a ser cristiano por una decisión ética o una gran idea, sino por el encuentro con un acontecimiento, con una Persona, que da un nuevo horizonte a la vida y, con ello, una orientación decisiva ${ }^{9}$.

Se ha de pensar en esa «hermosa experiencia de aquellos primeros discípulos que, encontrando a Jesús, quedaron fascinados y llenos de estupor ante la excepcionalidad de quien les hablaba, ante el modo cómo los trataba, correspondiendo al hambre y sed de vida que había en sus corazones ${ }^{10}$. El impulso misionero brota del deseo de abrir a los otros la posibilidad de ese mismo encuentro, de esa misma experiencia, como hace Andrés con Simón y Felipe con Natanael (cf. Jn 1, 35-48).

¿Cómo reproducir hoy ese acontecimiento? ¿Cómo provocar hoy ese encuentro?

\subsection{La Escritura, Iugar de encuentro con Cristo}

En primer lugar, hay que redescubrir que «Cristo se nos da a conocer en su persona, en su vida y en su doctrina por medio de la Palabra de Dios» ${ }^{11}$. La sagrada Escritura nos garantiza un contacto vivo e inmediato con Jesucristo, Palabra del viva del Padre ${ }^{12}$, en una relación vital en la que cada uno está llamado a entrar personalmente (VD 51). La singularidad de esta palabra bíblica reside en la inspiración (VD 19). Ésta no remite solamente a la acción del Espíritu Santo en el origen de esta palabra escrita (en los autores inspirados), sino también a la cualidad permanente de esa misma Escritura (en el libro inspirado). Desde la consideración del misterio de la Encarnación, estamos invitados a redescubrir

9. Deus Caritas est, 1. Esta categoría del «encuentro» aparecía ya como un eje en Ecclesia in America, cf., por ej., n. 12.

10. Aparecida, 244.

11. Benedicto XVI, Disc. Inaugural de la Conferencia de Aparecida, 3. A éste habrá que añadir -como hace el Doc. de Aparecida- otros «lugares de encuentro» (cf. nn. 250-257).

12. Cf. C. M. MARTINI, En el principio, la Palabra. Carta al clero y a los fieles sobre el tema: «La Palabra de Dios en la liturgia y en la vida», Bogotá 1995, 16. 
la dimensión sacramental de esta Palabra bíblica (VD 56), de donde deriva su inigualable eficacia salvífica ${ }^{13}$.

\subsection{La meta es la formación de discípulos}

La meta de la evangelización no consiste en conseguir adeptos para la lglesia, sino en formar discípulos de Jesús. Igual que Andrés y Felipe (cf. Jn 1, 3551), también nosotros estamos llamados a transmitir una experiencia personal y guiar a los demás al encuentro del único Señor y Mesías ${ }^{14}$. Es él quien puede introducirnos, a su vez, en su experiencia de Hijo (cf. Mt 11, 27), haciéndonos de verdad hijos del Padre. Ese descubrimiento de la paternidad de Dios señala el comienzo de una configuración progresiva con el Hijo y de una asunción cada vez más plena y convencida de su causa, de su misión. La percepción certera de un reinado de Dios ya presente en propia vida y en la historia (Mt 11, 4-5.25) es la motivación más fuerte de la tarea de anunciar y extender ese reinado a todas las personas y a toda la realidad. No anunciamos una idea o un proyecto futuro, sino «un hecho» (cf. VD 92) que cambia el horizonte de la historia y que interpela personalmente a todos. De allí surge «la urgencia y la belleza de anunciar la Palabra para que llegue el Reino de Dios» (VD 93).

La pluralidad de propuestas espirituales y la floración de tantos carismas dentro de la misma Iglesia nos puede llevar a identificarnos con tal o cual fundador, cuyas obras leemos, estudiamos y meditamos como alimento diario. Corremos el riesgo de olvidar que nuestra identidad cristiana se resume esencialmente en ser discípulos de Jesús. Y la evangelización se orienta hacia esa misma meta: formar discípulos del Señor.

\subsection{Configurados con Cristo}

El discípulo se forma en la escucha del Maestro: «Cada mañana Él despierta mi oído para que escuche como los discípulos» (Is 50,4). Esa atención llena de devoción a sus palabras y sus gestos ${ }^{15}$ lleva a una adhesión incondicional a su persona (cf. Jn 15, 15), a la participación en su propia vida y a una progresiva configuración con Él (cf. Gal 2, 20).

La invitación recurrente de Juan Pablo II y de Benedicto XVI a la escucha y a la familiaridad con la palabra de la Escritura deriva de la convicción de que

13. En tanto Palabra de Dios escrita, la palabra bíblica conserva ese «carácter performativo» del que habla VD 53.

14. Cf. Evangelii Nuntiandi, 46.

15. Con la misma delicadeza con que cuidamos el cuerpo eucarístico del Señor, procuramos también no dejar caer ni una sola de sus palabras, cf. ORíGENES, In Exod. hom. XIII, 3. Nos anima la convicción de que el mismo y único Logos de Dios hecho carne se encuentra en el sacramento eucarístico y en el sacramento de la Escritura, cf. S. JeRónImo, Commentarius in Ecclesiasten, 3, citado en VD 54. 
«la Palabra divina nos transforma» como transformó a María. En la Virgen podemos contemplar "una existencia totalmente modelada por la Palabra» de manera que ella «habla y piensa con la Palabra de Dios», «su querer es un querer con Dios» (VD 28). Es la primera creyente del Nuevo Testamento y la mejor discípula del Señor (cf. Mc 3, 35; Lc 1, 45; 11, 28).

\section{El Ministerio dEL PREsbítero}

Todos los bautizados son responsables del anuncio del Evangelio $(V D 90)^{16}$, pero un ministerio particular e insustituible seguirá siendo siempre el de los ministros ordenados, especialmente el del presbítero, que tiene como encargo primordial hacer que este anuncio del Evangelio llegue efectivamente a todos los hombres.

En verdad, «vida y ministerio» son una sola cosa en la existencia cristiana concreta del pastor, que encuentra su camino de santidad, de configuración con Cristo, «ejerciendo sincera e incansablemente sus ministerios» ${ }^{17}$.

\subsection{Primer oyente de la Palabra}

Muchas de las ponencias de los padres sinodales insistían en que «la Palabra de Dios es indispensable en formar el corazón del buen pastor». Y el papa lo convierte en una condición de su labor pastoral: «antes que ser transmisor... tiene que ser oyente de la Palabra». Esa declaración de principios se traduce concretamente en la necesidad de la «lectura personal frecuente» y el «estudio asiduo» (VD 79), pues de otro modo, estos pastores se volverían «predicadores vacíos de la palabra» ${ }^{18}$.

La vida espiritual -la vida según el Espíritu- se alimenta en primer lugar de la Palabra del Dios vivo, en la que «el Padre, que está en el cielo, sale amorosamente al encuentro de sus hijos» ( $D V 21)$ y en la que cada fiel reconoce la voz de su Pastor (cf. Jn 10, 4). En la vida del pastor, esta escucha de la Palabra es la fuente de su oración, la luz de su discernimiento, el alimento de su compromiso, el contenido de su predicación.

Hay un auténtico llamado a pasar de una relación «funcional» con la Escritura a una relación personal con Jesús que se encuentra en ella y en ella nos habla. Una relación que se cultiva y fortalece en un coloquio de amistad, deseado y

16. «Una nueva acción misionera, que no podrá ser delegada a unos pocos 'especialistas', sino que acabará por implicar la responsabilidad de todos los miembros del Pueblo de Dios», Novo millennio ineunte, 40.

17. Prebyterorum ordinis, 13.

18. Dei Verbum, 25; desarrollado ampliamente en Pastores dabo vobis, 26. Así lo pedían también las propositiones 31 y 32 . 


\section{Jorge Blunda Grubert}

buscado cotidianamente. La Biblia no es un simple depósito de verdades, de consejos y de promesas consoladoras para transmitir a los demás. Es la Palabra de Aquél a quien hemos decidido servir con la totalidad de nuestra humanidad. Antes de emprender la frenética actividad que exige el ritmo de nuestras parroquias, necesitamos adoptar la postura del discípulo, sentarnos a escuchar lo que el Señor quiere de nosotros y de su comunidad (cf. Lc 10, 38-42).

\subsection{Palabra viva de Dios para su pueblo}

Antes que con su palabra o su acción pastoral, el presbítero predica con su vida misma. Efectivamente, la interpretación última de la Escritura no la hacemos con el discurso o los escritos, sino con un estilo de vida. Era la Madre Teresa de Calcuta quien exhortaba a los cristianos a un testimonio coherente, ya que la vida de los creyentes es en la mayoría de los casos la única Biblia que leerá la mayoría de la gente ${ }^{19}$. Al esfuerzo por traducir en todas las lenguas el texto bíblico, se ha de sumar el de «traducir en gestos de amor la Palabra escuchada, porque sólo así se vuelve creíble el anuncio del Evangelio» (VD 103). Es el idioma que todos entienden y, en algunas circunstancias, el único que pueden entender. En ambientes secularizados y hostiles, personas como la beata Teresa o el beato Carlos de Foucauld enseñan cómo, hablando poco, se puede decir mucho.

Hemos de invertir mucho tiempo, energías y recursos en la planificación y la programación de las acciones pastorales. Esta tarea sigue siendo insustituible e impostergable, sobre todo para un presbítero o un obispo. Pero hoy aparece una preocupación complementaria: la preocupación por el «ser» del pastor, que se expresa y se alimenta -o no- en su «hacer». Así, para el papa Benedicto, el primer servicio del sacerdote es su propio testimonio de oyente de la Palabra: configurado con su Maestro, también «sus palabras, sus decisiones y sus actitudes han de ser cada vez más una transparencia, un anuncio y un testimonio del Evangelio» (VD 80). Sólo así será efectivamente un «sacramento de Cristo pastor».

\subsection{Servidor de la Palabra}

En los ámbitos eclesiásticos hemos podido percibir durante años una insistencia (un tanto unilateral) en la relación del presbítero con la Eucaristía. Frente a ello, se yerguen como un monumento las palabras con las que el Concilio comienza a enumerar sus munera: primum officium habent Evangelium Dei omni-

19. La misma visión del papa que, hablando de la vida de los santos, cita la expresión de San Gregorio Magno, Moralia in Job 24, 8, 16: viva lectio est vita bonorum (VD 48). Más recientemente ha dicho: «Los cristianos debemos ser un mensaje viviente, más aún, en muchas ocasiones somos el único Evangelio que los hombres de hoy todavía leen» (Benedicto XVI, Homilía en la misa del Miércoles de Cenizas, 9 de marzo de 2011). 
bus evangelizandi ${ }^{20}$. Es este anuncio el que suscita la fe, que comunica la vida nueva en Cristo (cf. Rm 10, 7; 2Cor 11, 7). Sólo a partir de esta fe se puede edificar la Iglesia, que celebra los misterios.

«Dios habla en la Escritura por medio de hombres y en lenguaje humano» (DV 12a; cf. nn. 8c y 21) ${ }^{21}$. La Sagrada Escritura es mediación de una Revelación que ha de entenderse siempre un acontecimiento salvífico. Nosotros estamos llamados a hacer posible este acontecimiento para todos los hombres, en todas las circunstancias en las que éstos se encuentren. Estamos ahí, para facilitar hoy el encuentro personal de cada uno con Cristo, Palabra del Padre, para que se realice esa «contemporaneidad de Cristo respecto del hombre de cada época», esa «relación vital», ese «diálogo nupcial» que va introduciéndonos en la vida plena (VD 51).

Nuestro ministerio deberá despertar una verdadera pasión por la Palabra, por la que cada uno pueda decir, como el profeta Jeremías: «Cuando encontraba palabras tuyas las devoraba; tus palabras eran mi gozo y la alegría de mi corazón» (Jr 15, 16). Esta pasión por la Palabra de Dios se convertirá en pasión por la evangelización, porque ella se convierte en «un fuego que te quema por dentro» (Jr 20, 9). El que de veras ha sido encendido por esta Palabra, ya nunca podrá acallarla.

\section{Un ESTILO PASTORAL INSPIRADO EN LA REVELACIÓN BÍBLICA}

Ya el Concilio expresaba con fuerza que «toda la predicación de la Iglesia, como toda la religión cristiana, se ha de alimentar y regir con la Sagrada Escritura» (DV 21). No sólo los contenidos de nuestra enseñanza, sino la modalidad misma de nuestro ministerio encuentra en la Escritura su norma y su guía. Debería llegar el momento en que la actividad pastoral esté «totalmente impregnada por el pensamiento, el espíritu y las actitudes bíblicas y evangélicas, a través de un contacto asiduo con los mismos textos» ${ }^{22}$. De ese modo, la pedagogía de la fe se inspirará en la misma pedagogía de Dios.

Si nos tomamos en serio las insinuaciones que el Espíritu del Señor nos hace a través de los cambios culturales y las indicaciones del magisterio en estas últimas décadas, no podremos esquivar la necesidad de una verdadera «conversión pastoral»23.

20. Presbyterorum Ordinis, 4.

21. VD 72 recuerda que «la Bilbia es el instrumento 'con el que Dios habla cada día a los creyentes' (JERÓNIMO, Epistula 133, 13)».

22. Ampliando el alcance de lo que Catechesi tradendae, 27 -citada en VD 74-aplica sólo a la tarea catequística.

23. Es la expresión empleada por los obispos latinoamericanos en Aparecida (cf. nn. 366370) y por diversos episcopados de ese continente. 


\section{Jorge Blunda Grubert}

\subsection{Dimensión personal}

Una de las novedades más llamativas de la Dei Verbum está en el tono personal y personalista de su lenguaje. La idea misma de revelación se expresa en ella, no en el lenguaje de las esencias y las nociones, sino en de las personas y sus relaciones. Dios no reveló verdades abstractas, sino que «quiso revelarse a sí mismo y darnos a conocer el misterio de su voluntad (...) para invitarnos y recibirnos en su comunión» ( $D V$ 2). Esta forma de concebir la revelación lleva, a su vez, a una forma precisa de entender la tarea evangelizadora: la misión se desarrolla en el plano interpersonal, la pastoral busca establecer un modo nuevo de relacionarse entre las personas. Lo que importa, en primer lugar, es el vínculo que se crea y que hace posible transmitir convicciones y contagiar actitudes ${ }^{24}$.

\subsection{Estilo dialogal}

Es precisamente nuestra capacidad de escuchar la que puede mostrar hoy que «Dios escucha al hombre y responde a sus interrogantes» (VD 23). La evangelización, como la revelación, sigue el camino del diálogo. «Hace falta, aun antes de hablar, escuchar la voz, más aún, el corazón del hombre, comprenderlo y respetarlo en la medida de lo posible y, donde lo merezca, secundarlo. Hace falta hacerse hermanos de los hombres en el mismo hecho con el que queremos ser sus pastores, padres y maestros. El clima del diálogo es la amistad. Más todavía, el servicio» ${ }^{25}$.

«El diálogo que, antes de hacerse coloquio, debe dirigir la propia atención al "otro», es decir, a aquél con el cual queremos hablar»" ${ }^{26}$. La misión, entendida de este modo, no nos pone frente a meros «destinatarios» de un mensaje, sino frente a «interlocutores» con quienes nos encontramos para testimoniar juntos el evangelio ${ }^{27}$. En este diálogo, estamos llamados a escuchar ante todo a los pobres y aprender de ellos (cf. VD 107). Un diálogo que hemos de abrir nosotros espontáneamente, un diálogo que nace de la caridad, no se ajusta a los méritos del otro, no obliga a nadie a acogerlo, procede gradualmente, con humildad y paciencia ${ }^{28}$.

\subsection{Clima amical}

«Dios invisible habla a los hombres como amigos, movido por su gran amor y mora con ellos, para invitarlos a la comunicación consigo y recibirlos en su compañía» (DV 2). La labor pastoral no puede desenvolverse en el clima empresarial

24. Cf. Conferencia Episcopal Argentina, Carta pastoral sobre la Misión Continental, Buenos Aires 2009, 15-17. Por eso, no se habla tanto de «destinatarios», sino de «interlocutores».

25. Ecclesiam suam, 33.

26. Redemptor Hominis, 11.

27. Cf. Conf. Episc. Argentina, Carta pastoral sobre la Misión Continental, 16.

28. Cfr. Ecclesiam suam, 29. 
de la eficacia y la eficiencia, sino en el clima gratuito de la amistad y el amor. Si son las personas las que cuentan, entonces el ministerio se ha de desenvolver según el modelo de Pablo, que les dice a los de Tesalónica: «Tanto os queríamos que ansiábamos entregaros, no sólo el evangelio de Dios, sino también nuestras propias vidas. ¡A tal punto llegaba nuestro amor por vosotros!» (1Tes 2,8$)$.

\subsection{La atención a los signos de los tiempos}

Dentro de esta capacidad de escuchar habría que incluir la escucha de la Palabra de Dios en el mundo y en la historia, tal como lo ha indicado el Concilio Vaticano II no sólo con sus textos, sino con la actitud que ha asumido frente a ese mundo y esa historia. A la secuencia Verbum Dei - Verbum in Ecclesia Verbum mundo, que estructura la exhortación apostólica, habría que añadir también una consideración del verbum mundi en el que la fe discierne el Verbum in mundo.

Si se toma en serio el sentido analógico que asumen los términos «Palabra de Dios» (cf. VD 7), entonces no sólo hay una Palabra de Dios en la Escritura, en la Biblia; también hay una Palabra de Dios en la historia y la vida presente. Con toda verdad decimos que Dios sigue hablando en medio de la existencia de cada uno y a través de los grandes acontecimientos contemporáneos que encarnan auténticos valores y aspiraciones humanas y crean un consenso universal, por orientarse hacia una promoción global de la humanidad. Son para los creyentes una verificación de la presencia y la acción de Dios en la historia, "señales que infunden esperanza de tiempos mejores»" ${ }^{29}$. El Concilio nos ha enseñado a "auscultar, discernir e interpretar» esos signos de los tiempos ${ }^{30}$. Señalan el modo adecuado de anunciar, con palabras y gestos, el perenne mensaje del Evangelio de manera que sea percibido como buena noticia y respuesta divina a las ansias y deseos profundos que el mismo Espíritu de Dios ha encendido en el corazón de los hombres y de la humanidad. En ello se juegan la eficacia de la tarea evangelizadora y la fidelidad de la Iglesia al camino seguido por su Señor.

La convicción de que «la Palabra no nos es originalmente ajena» (VD 50) no hay que aplicarla restrictivamente a la Iglesia, a la comunidad de los creyen-

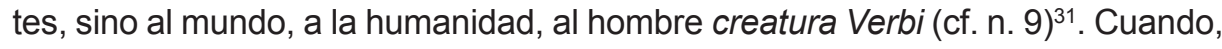
de la mano de la Iglesia, la Palabra llega hoy a este mundo, sigue siendo verdad que llega "a su casa», «a los suyos» (Jn 1, 11), buscando quiénes la reciban.

29. JUAN XXIII, Humanae salutis, 3.

30. Cf. Gaudium et spes, nn. 4, 11 y 44.

31. El contexto del n. 50 muestra que esa intepretación amplia es fiel a la intención del papa, que añade a continuación: «la creación ha sido querida en una relación de familiaridad con la vida divina». 


\section{LA UTILIDAD PASTORAL DE UNA SERIA FORMACIÓN BÍBLICA}

¿Qué ventajas puede proporcionarle a un pastor su preparación como biblista? Una pregunta que me hago a mí mismo, después de treinta años repartidos entre el estudio de la Escritura y la directa responsabilidad pastoral, al frente de diversas comunidades, sea en el nivel parroquial o en el plano diocesano. Y caigo en la cuenta de que esa preparación tan específica ha sido quizá el mejor equipamiento de que podía pertrecharme para enfrentar las tareas que, de hecho, se me han encomendado.

\subsection{Hermenéutica y relaciones humanas}

Una adecuada formación bíblica capacita al presbítero para un diálogo fecundo, pues le ha habituado a la mirada atenta, a reconocer la alteridad, al respeto por la palabra ajena y a la valoración positiva de las distancias que le separan del otro. «La hermenéutica es la clave de toda buena relación humana sana, positiva, feliz, enriquecedora: apunta a una mejor comunicación con los demás, supone confianza en las posibilidades del encuentro y en el poder de la palabra» ${ }^{32}$.

Esta capacidad se aplica, en primer lugar, en la relación con las personas, en el diálogo pastoral, propio del acompañamiento espiritual o de la animación de los diferentes grupos y comunidades. Esta «prevención hermenéutica» nos advierte sobre la necesidad de «codificar» adecuadamente el mensaje que queremos transmitir a los demás, teniendo en cuenta las condiciones del «receptor». Y nos orienta a un conocimiento más real y profundo de la persona que, como «emisor», está manifestándose a nosotros.

Pero esta actitud hermenéutica también es esencial en el momento del análisis de las realidades en las que nos toca ejercer su ministerio. También éstas son «textos» complejos, tejidos de innumerables factores humanos que se expresan sólo en parte y en diferentes medidas, en las situaciones, acontecimientos y procesos que podemos percibir y constatar.

La atención a los «con-textos» y «pre-textos» resulta también un entrenamiento fructífero a la hora de comprender a las personas, los procesos sociales y las situaciones problemáticas que surgen en la vida pastoral. «Para leer la Biblia respetuosamente era necesaria una actitud semejante a la que debe tener quien pretenda comprender a personas que han nacido y viven en una cultura diferente ${ }^{33}$.

Tantas veces, los clérigos sólo nos escuchamos a nosotros mismos, encerrados en nuestras preocupaciones personales o de grupo y en nuestra propia

32. Esta aplicación de las cuestiones hermenéuticas a las relaciones interpersonales es el tema de V. M. FERnÁNDEZ, Quiero comunicarme contigo, Buenos Aires 2000.

33. S. GuIJARRO, «La Biblia y al antropología cultural», Medellín 88 (1996) 87. 
enciclopedia cultural. En nuestros análisis de la sociedad, vemos sólo aquello que queremos ver, ejerciendo inconcientemente una especie de «inatención selectiva» ante la realidad objetiva que tenemos ante nuestros ojos y que nos hemos hecho incapaces de ver.

La práctica de la traducción. El esfuerzo constante por captar los contenidos y connotaciones del texto original y por verterlo en expresiones equivalentes del lenguaje de los destinatarios, pensando siempre en las resonancias que cada término puede despertar en los lectores/oyentes, habitúa a una delicadeza en el manejo de la lengua tanto en la predicación como en el diálogo personal, y obliga a una atención permanente a los destinatarios.

El paradigma del canon bíblico. En medio de las tensiones ideológicas que afectan continuamente a la comunidad eclesial y frente a la tentación de la eliminación recíproca, la formación del canon bíblico representa verdaderamente un modelo alternativo. En él, la integración y la complementariedad sustituyen a la lógica de la exclusión y el integrismo. Seguidores de las corrientes deuteronomistas, sacerdotal, profética, pueden encontrarse y reconocerse en una Biblia, que es de todos y no es de nadie en exclusiva. Gálatas y Santiago, las cristologías ascendentes y descendentes, la eclesiología de Corintios y la de Efesios, todas entran y conviven saludablemente en el Canon. La conciencia de la limitación constitutiva de toda objetivación humana de la voluntad de Dios y de todo proyecto comunitario a lo largo de la historia del Pueblo de Dios, exorciza todas los intentos necesarios de planificación pastoral, modelos, criterios, estrategias.

\subsection{Actualización}

Si la Iglesia «no considera la Biblia simplemente como un conjunto de documentos históricos concernientes a sus orígenes, sino como palabra que Dios dirige a ella y al mundo entero en el tiempo presente ${ }^{34}$, entonces se imponen al ministerio pastoral las tareas ineludibles de la actualización y la inculturación de esa palabra de Dios.

Ya la misma Biblia atestigua la práctica de la actualización. De hecho, la Escritura crece en virtud de esa necesidad de releer y actualizar, hasta formar el corpus bíblico. Y ese dinamismo perdura aun después de la puesta por escrito, en la tradición interpretativa. Era la convicción que inspiraba a los rabinos y lo que percibían los Padres, cuando decían que «la Escritura crece con quien la lee» ${ }^{35}$.

La Biblia es una escuela donde aprendemos a leer los hechos de nuestra historia y las experiencias de nuestra vida a la luz de la palabra de nuestro Dios, de

34. Pont. Com. BíB., La Interpretación de la Biblia en la Iglesia, IV.

35. S. Gregorio MAgno, Hom. In Ezechielem 1, 7, 8, citado en VD 30. Nos lo recuerda Dei Verbum 8: «Haec ... Traditio ... crescit ... ex intima spiritualium rerum quam experiuntur intelligentia». 


\section{Jorge Blunda Grubert}

su promesa de amor y de su designio de salvación. Es el testimonio de una comunidad que busca discernir la voluntad de su Dios en cada etapa de su camino histórico y, en ese sentido, constituye un paradigma de una tarea permanente de la Iglesia universal y de las diversas Iglesias locales. En esta tarea los pastores desempeñan un papel indispensable ${ }^{36}$, incluso en instancias tan cotidianas como la homilía o la iluminación de los problemas sociales del momento.

La misma Biblia traza caminos para la actualización: «textos antiguos son releídos a la luz de circunstancias nuevas» ${ }^{37}$. La convicción creyente acerca de la actualidad de la palabra bíblica, por un lado, y de la valencia salvífica de la actualidad histórica, por otro, establece una circularidad hermenéutica. Para el lector de la Biblia, también los hechos actuales son elocuentes, hablan de Dios y de parte de Dios. El Dios de la Biblia sigue obrando y se sigue revelando hoy.

La Biblia tiene una plenitud que va mucho más allá de los que nosotros hayamos podido descubrir en una determinada circunstancia. Contiene una «reserva de sentido» ${ }^{38}$. Eso hace posible que cada vez que se las lea, se pueda encontrar en ellas cosas nuevas ${ }^{39}$. Éstas no podrán contradecir las anteriores lecturas, pero las enriquecerán con una verdadera novedad que brota de su relación con las circunstancias inéditas desde las cuales se está produciendo la lectura. «El mensaje bíblico puede a la vez relativizar y fecundar los sistemas de valores y las normas de comportamiento de cada generación» ${ }^{40}$.

Esta tarea de actualización del mensaje bíblico no es una labor opcional, sino necesaria; pues los «textos han sido elaborados en función de circunstancias pasadas y en un lenguaje condicionado por diversas épocas». Es necesario relacionar su mensaje con las circunstancias presentes y expresarlo en un lenguaje adecuado a la época actual. Todo esto «presupone un esfuerzo hermenéutico que tiende a discernir a través del condicionamiento histórico los puntos esenciales del mensaje» ${ }^{41}$.

La actualización se realiza gracias al dinamismo de la tradición viviente de la comunidad de fe. Esa «tradición» es la vida misma de la Iglesia. Pues el pueblo de Dios no es sólo un destinatario o receptor; es también el «soporte» o vehículo de esa tradición y de esa Palabra viva.

Hemos de comenzar por reconocer que «toda lectura de la Biblia es forzosamente selectiva». No sólo la lectura feminista o la liberacionista. También la del exégeta académico, la del pastor en su homilía y la del dicasterio romano. Para ser «objetivo», respetuoso de la Palabra de Dios, cada uno ha de saber

36. Cf. Gaudim et spes, n. 11.

37. Int.Bib.Igl., IV.A.

38. J. S. CROATto, Hermenéutica bíblica. Para una teoría de la lectura como producción de sentido, Buenos Aires 1994, 62-63, 105, 123-124.

39. Cf. SAn Efrén, Com. al Diatéssaron 1, 18-19.

40. Int.Bib.Igl., I.IV.A.1.

41. Int.Bib.Igl., I.IV.A.1. 
que está leyendo sólo un aspecto, ser consciente de su punto de vista y aceptar que hay otros tan válidos como el suyo. "Las desviaciones serán evitadas, si la actualización parte de una correcta interpretación del texto y se efectúa en la corriente de la tradición viva, bajo la guía del Magisterio eclesial».

Le tenemos miedo a la parcialidad y, sin embargo, la vida está hecha de parcialidad, es provisoria e imperfecta. Los riesgos no nos eximen de la necesidad de estas relecturas y de la actualización, para «hacer llegar el mensaje de la Biblia a los oídos y al corazón de nuestra generación» ${ }^{42}$.

\subsection{Inculturación}

A este esfuerzo de actualización, le acompaña el esfuerzo de inculturación, que asegura el enraizamiento del mensaje bíblico en los más diversos terrenos. Para eso, busca «una interpretación que ponga el mensaje bíblico en relación más explícita con los modos de sentir, de pensar, de vivir y de expresarse, propios de la cultura local ${ }^{43}$. Este imperativo pastoral obedece a este principio tantas veces proclamado por los Padres de la Iglesia: «Lo que no es asumido no es redimido» ${ }^{44}$.

Es una tarea que se orienta en último término a la formación de una «cultura local cristiana», que abarca todas las dimensiones de la existencia. Quizás pensemos que ésta es una labor propia de los misioneros, inmersos en realidades humanas extrañas a Evangelio y a la cosmovisión que de él deriva. Pero no hay que olvidarse que ésta es también la situación de la mayoría de nuestras sociedades, y que cada generación que nace es nuevamente «tierra de misión».

\section{LA ANIMACIÓN BÍBLICA DE LA PASTORAL}

\subsection{Historia de una opción pastoral}

Unas de las fecundas corrientes de renovación espiritual, pastoral y teológica que prepararon ánimo eclesial para el Concilio Vaticano II fue el movimiento bíblico. Éste tenía una expresión muy concreta en el amplio apostolado bíblico que se desarrollaba en los distintos niveles y ambientes y buscaba iniciar a los lectores de la Biblia en el conocimiento de los elementos literarios, sociales, históricos, culturales o religiosos que ayudan a entender correctamente el texto y su sentido original. Es el tiempo de la proliferación de las traducciones de los textos originales a las lenguas modernas (pensemos en las ediciones de Nácar-Colunga en España, de Straubinger en Argentina, entre otras), las confe-

42. Int.Bib.lgl., IV.A.3.

43. Int.Bib.Igl., IV.B.

44. Citado por el decreto Ad Gentes, 3. 


\section{Jorge Blunda Grubert}

rencias bíblicas, los cursos de cultura bíblica, la organización de las semanas bíblicas, la difusión del ficher biblique de Th. Maerten, del vocabulaire biblique del X. Léon-Dufour, y de primera edición de La Biblia de Jerusalén...

El Concilio ha ayudado a prestar aún más atención a la Palabra de Dios, al punto que en muchas diócesis y en algunos países, se llegó a constituir una verdadera «pastoral bíblica», entendida como una de las pastorales especializadas, que tiene como objeto la Biblia y la emplea como el medio privilegiado de evangelización. Esta área bíblica aparece entonces necesariamente dentro del diseño orgánico de la pastoral de conjunto ${ }^{45}$ y en coordinación con otras áreas, como la catequesis de adultos, la pastoral penitenciaria, el diálogo ecuménico o la pastoral misionera. Éste es el tiempo de los círculos bíblicos, la revisión de vida a la luz del Evangelio, la lectura popular, las comunidades eclesiales de base, los grupos de lectio divina o de «lectura orante» de la Biblia en sus diversas formas. El interés de estas iniciativas es la comprensión del sentido actual del texto bíblico. Se lee el texto desde los diversos contextos existenciales de los lectores y se lee la vida y la historia a la luz de esos textos. Se ha pasado de un interés exegético a una preocupación hermenéutica.

Pero hoy estamos en una nueva etapa, en la que la Palabra de Dios busca una presencia transversal en todas las áreas y acciones pastorales. Es cierto que las tareas de una pastoral bíblica siguen siendo indispensables, pues hay -y siempre habrá- mucha gente que no conoce suficientemente la Palabra de Dios, que no ha tenido ocasión de orar con la Biblia y ni siquiera tiene una traducción adecuada. Pero su presencia en la misión de la Iglesia ya no se entiende sólo como la de un instrumento útil, o el objeto de una acción pastoral específica, sino como la fuente de inspiración y la referencia constante de todas las acciones. Se ha pasado así de la pastoral bíblica a la animación bíblica de toda la pastoral ${ }^{46}$.

La animación bíblica de la pastoral supone haber redescubierto la Biblia como elemento de un acto comunicativo amplio y coherente: la revelación de Dios a su pueblo. Su acercamiento a los textos responde a la convicción de encontrar en cada uno de ellos la propuesta divina de un modo de creer y obrar para los cristianos. Obedece, entonces, a la percepción de su dimensión pragmática: busca en él un modelo de acción ${ }^{47}$.

45. Sobre la «pastoral bíblica» dentro de la «pastoral de conjunto», resulta de gran interés C. Mora PAZ, ¿Para qué la Biblia? La Sagrada Escritura en la vida la Iglesia, México, D.F. 1994, 25-41 y 65-92.

46. Cf. a este respecto, el documento de la CONFERENCIA EPISCOPAL DE CHILE, Orientaciones para la animación bíblica de la pastoral de la Iglesia en Chile, Santiago de Chile 2006, especialmente pp. 9 y 12-16.

47. Cf. el artículo de F. LENTZEN-DEIS, «El relato de la pasión, ¿un modelo de acción?», en la obra de colaboración que él mismo ha coordinado Avances metodológicos de la exégesis para la praxis de hoy, Bogotá 1990, 18-21. 


\subsection{Los principios de la $A B P$}

Se ha de pensar no sólo en proponer los contenidos de la Sagrada Escritura, sino también en seguir su método, en adoptar la misma pedagogía que Dios manifiesta en ella, a la hora de pensar el itinerario y los proyectos pastorales concretos $^{48}$.

Una aplicación ejemplar y concreta se tiene en el método adoptado por algunas diócesis o conferencias episcopales enteras en América Latina: para elaborar sus propuestas pastorales han asumido la costumbre de tomar -sobre todo de los evangelios- un texto suficientemente extenso y significativo, al que dedican normalmente un capítulo inicial en su documento programático, y lo asumen como elemento estructurador de su propuesta.

Según esta modalidad, no se usa el texto en cuestión como «argumento bíblico», para sustentar unas directrices gestadas previamente y a partir de otras premisas, sino como la fuente inspiradora de una planificación pastoral. Esto supone la contemplación del texto y la asimilación del modelo de acción que éste postula. A partir de allí, se comienza a pensar en un plan que obedezca a estas actitudes, a estos cauces y criterios. Los personajes del texto se convierten en paradigma de vida cristiana y modelo de agentes evangelizadores. El mensaje central del texto adquiere una significación transversal y se tiene en cuenta a lo largo de todo el itinerario pastoral.

El Documento de Santo Domingo (1992) proponía la historia de los discípulos de Emaús, en Lc 24, 13-35, como modelo de un itinerario pastoral para todo el pueblo de Dios en Latinoamérica. Las líneas pastorales del episcopado chileno se inspiran en Jn 1, 35-42 ${ }^{49}$.

De manera análoga, un itinerario catequístico podría brotar de la narración que hace Jn 9 de la curación del ciego de nacimiento. La historia de la Samaritana en Jn 4 podría ser paradigmática para la propuesta de un plan de evangelización en el contexto de la nueva evangelización.

\subsection{Las tareas de la animación bíblica de la pastoral}

En el único número dedicado a este tema, VD 73 explica claramente que no se trata «de añadir algún encuentro [bíblico] en la parroquia o la diócesis, sino de lograr que las actividades habituales ... se interesen realmente por el encuentro personal con Cristo que se comunica en su Palabra». Pero, de hecho,

48. De modo ejemplar podemos recordar la experiencia de los 22 años del Card. Martini al frente de la Archidiócesis de Milán: las cartas pastorales, los retiros espirituales, los grupos Samuel, la escuela de la Palabra, la cátedra de los no creyentes, etc. Cf. «La centralidad de la Palabra en la vida de la Iglesia. La animación bíblica de la pastoral», Pastores 42 (2008) 30-37.

49. Discípulos y misioneros de Jesucristo para que en él nuestro pueblo tenga vida. Orientaciones pastorales 2008-2012, Santiago de Chile 2008, esp. 15-23. 
parece quedarse más bien en el plano de una más amplia y profunda «pastoral bíblica», sin percibir todo lo que las propositiones y ponencias contenían de experiencia y de anhelo ${ }^{50}$.

En compensación, el documento ha aplicado sistemáticamente este imperativo de la «conversión bíblica» a todas las tareas de la pastoral. Éste es «el ámbito propio en el que recorrer un itinerario personal y comunitario con respecto a la Palabra de Dios, de modo que ésta sea realmente el fundamento de la vida espiritual» (VD 72). Además, ha subrayado, como nunca antes, la centralidad de esta Palabra en la celebración litúrgica de la Iglesia (nn. 52-71), curiosamente colocada aparte de «la vida eclesial» (nn. 72-89).

El ministerio pastoral está en origen de todo este abanico de tareas que tejen la vida y la misión de la Iglesia. De manera que la segunda y la tercera parte del documento pontifico pueden entenderse como un «directorio», que busca reorientar el ejercicio de este ministerio.

Se destaca, en primer lugar, la liturgia como ámbito de un ministerio propio y específico. En este contexto, la homilía pide esa «familiaridad y trato asiduo con el texto sagrado» que permitan al predicador «mostrar a Cristo» y «ser el primero en dejarse interpelar por la Palabra de Dios que anuncia» (VD, 59). Se pueden indicar muchos elementos que ayuden a la preparación de una buena homilía, pero hay una preparación remota que no se puede suplir. «Un predicador es un contemplativo de la Palabra y también es un contemplativo del pueblo» ${ }^{51}$

La catequesis debería consistir fundamentalmente en la formación bíblica de los cristianos, pues tiene como primera fuente la Sagrada Escritura. Ningún texto ni catecismo podrá sustituir el contacto directo con el texto bíblico, que provoca un encuentro con Cristo. Velar por la orientación bíblica de la catequesis exige en primer lugar una dedicación a la formación específica de los catequistas y de todos los agentes de pastoral.

Una instancia sencilla y eficaz es la «Escuela de la Palabra», que puede tener diferentes versiones. Es una oportunidad especial para un contacto directo y cercano del párroco con todos los que quieren conocer mejor la Biblia, aprender a orar con ella y a iluminar la propia vida con la Palabra de Dios. En una reunión semanal abierta, el pastor de esa comunidad introduce oportunamente al misterio de la sagrada Escritura, y guía el estudio y la lectura creyente de algún libro bíblico. No será fácil encontrar excusas para relegar o postergar una tarea como ésta, que posibilita el ejercicio concreto de una dimensión esencial del propio ministerio. En este espacio brotan espontáneamente diversas vocaciones y servicios para la comunidad.

50. Cf. sobre todo las alocuciones de los obispos latinoamericanos, como las de R. Damasceno Assís, S. Silva Retamales y las propuestas n. 30.

51. V. M. FERnÁndeZ, Cómo interpretar y cómo comunicar la Palabra de Dios. Métodos y recursos prácticos, Buenos Aires 2008, 107. 
La consolidación de todas las vocaciones depende de su enraizamiento en la Palabra de Dios (cf. VD 77-85). Hay toda una pastoral vocacional que deriva del desempeño adecuado y pleno del ministerio de la Palabra. Enseñar a orar la Palabra y a discernir bajo su luz la voluntad de Dios es la mejor ayuda que el pastor puede brindar a sus hermanos. El discernimiento personal y comunitario es un ejercicio cotidiano en el seguimiento del Evangelio.

Se espera que un presbítero sea maestro de esta «lectura orante» de la Escritura, que alimente y sostenga la vida espiritual y el compromiso apostólico de los cristianos. Para eso, los talleres de oración, los retiros o las semanas bíblicas brindan un espacio oportuno ${ }^{52}$.

Latinoamérica tiene una tradición propia de lectio divina, que se cultiva en los "círculos bíblicos» o "asambleas familiares», ya sea en el contexto de las pequeñas comunidades, de los grupos de la catequesis familiar o de muchas asociaciones de apostolado. Este método tiene la forma de una collatio, pero se apoya en la presencia simultánea de tres elementos: la vida con sus experiencias y vicisitudes, el texto bíblico leído de manera seria y la comunidad de fe en la que se confronta y verifica la lectura creyente del texto y de la vida.

Para llevar adelante esta tarea, hace falta preparar adecuadamente a algunos animadores, mediante cursos de iniciación a la lectura de la Biblia y talleres para animadores de grupos bíblicos. De manera sencilla se pueden proporcionar los contenidos básicos y los métodos apropiados para la formación y animación de estos pequeños grupos. En esto también se muestra el «efecto multiplicador» de las semanas y las escuelas bíblicas.

«El pueblo de Dios se congrega primeramente por la palabra del Dios vivo, que con toda razón es buscada en la boca de los sacerdotes» ${ }^{53}$. Un desafío para nuestra forma concreta de concebir y vivir el ministerio. El acontecimiento sinodal del año 2008 y la exhortación pastoral son una preciosa orientación e incentivo para estos tiempos de nueva evangelización.

52. Una semana bíblica diocesana puede ser preprarada durante un mes anterior, mediante reuniones parroquiales, realizadas con la ayuda de una guía proporcionada por el equipo diocesano. Finalmente tienen lugar una serie de encuentros masivos, que pueden consistir en: a) una conferencia introductoria del tema o texto del año, b) una mesa panel ecuménica o interreligiosa en la que las varias tradiciones expresan su experiencia de lectura, c) un debate en torno a una película u obra de teatro que encarne de alguna manera el mensaje de los textos trabajados, d) un taller de estudio de textos en pequeños grupos, seguido de una puesta en común y e) una velada de oración bíblica, animada por alguna de las Iglesias que han participado. Así funcionaba la experiencia que animamos en nuestra Archidiócesis durante varios años.

53. Presbyterorum ordinis, 4. 